\title{
La Profesionalización De La Docencia Universitaria Y Su Influencia En El Desarrollo De Las Competencias Pedagógicas En La Formación De Docentes En El Instituto Superior De Ciencias De La Educación (ISCED) De Benguela, Angola
}

\author{
Santiago Alonso-García (PhD) \\ Universidad de Sevilla, España \\ Elena Sánchez-Vega (PhD) \\ Universidad de Málaga, España \\ Ernesto Inocêncio (PhD) \\ Universidad de Granada, España
}

doi: 10.19044/esj.2017.v13n13p449 URL:http://dx.doi.org/10.19044/esj.2017.v13n13p449

\begin{abstract}
The presentation of the results of the present study was used to fundamentally analyze the influence of professionalism of university teaching in the development of the pedagogical competences of students in teacher training at the Higher Institute of Educational Sciences (ISCED) in Benguela. This study was carried out on the theme based on reference. The research carried out is of the descriptive type, whose data collection was quantitative and qualitative, from the determined sample. It is made up of teachers, students, and school board members. This, however, is a quantitative and qualitative study. Based on the data collected, the paper concludes on the lack of planning in pairs of the teaching work, the lack of a specific team for the supervision of the teaching work, and the fact that there is no specific criterion in the entrance periphery of teaching candidates.
\end{abstract}

Keywords: Influence, professionalism, university teaching, pedagogic skills, teacher training

\section{Resumen}

La presentación de los resultados del estudio sobre el tema en cuestión, con el objetivo de analizar principalmente la influencia de La profesionalización de la docencia universitaria y su influencia en el desarrollo de las competencias pedagógicas en la Formación de docentes en el Instituto Superior de Ciencias de la Educación (ISCED) de Benguela 
(Angola). La investigación es descriptiva, cuya recolección de datos fue cuantitativo y cualitativo. La muestra dada consiste en: docentes, estudiantes y miembros de la junta escolar. Sobre la base de los datos recogidos, la investigacion se presenta con una conclusiones claras: la falta de planificación de los compañeros de trabajo, la falta de un equipo específico para la orientación y el hecho de no tener un criterio específico en el perifl de contratacion de los candidatos.

Palabras clave: Influencia, profesionalizacion, dcencia universitaria, competencias pedagógicas, formación docente

\section{Introducción}

En el siglo XXI, la "era del conocimiento", es necesario revisar y replantear la práctica docente y la producción de conocimiento en la educación superior. Para Tardif y Lessard (2005:267) ser docente no es nada más que "[...] que un conjunto de interacciones personalizadas con los estudiantes con el fin de conseguir su participación en su proceso de formación y satisfacer diferentes necesidades ".

Este proceso de enseñar al alumno, requiere un conjunto de actitudes y habilidades por parte del profesor que enseña, ya que el aprendizaje del estudiante no va a surgir de la nada, sino que "se trata de un proceso". El profesor universitario de docentes de formación infantil, necesita estar motivado, preparado y listo.

Es fundamental tener conocimiento de los procedimientos pedagógicos, didácticos y psicológicos para una educación de calidad en la educación superior. En primer lugar, el docente debe darse cuenta de que tiene la responsabilidad de desarrollar el programa de formación, así como el papel que juega en el desarrollo de habilidades profesionales.

Por lo tanto, se insiste en que el docente tiene que entender que su forma de ser, es también una de las formas correctas para que sus alumnos aprendan.

Demo (2004) habla de la docencia mayéutica, pero ¿̇los estudiantes prefieren docentes innovadores o tradicionales? De hecho, la mayoría de los estudiantes que no tienen la visión de crecimiento personal y profesional prefiere docentes tradicionales, con el argumento de que obtener el conocimiento de forma tradicional, es más fácil caminar por los "caminos de descubrimiento", y también porque como se suele decir "los daños del pensamiento, provocan sufrimiento ". Por tanto, de poca o ninguna utilidad resulta la innovación para el profesor el cual se esfuerza para que el estudiante se convierta en un investigador. Está también el estudiante se siente parte de este proceso continuo de aprendizaje, pero en menor medida. 
Preguntar acerca del desarrollo de las competencias de la enseñanza, implica la necesidad de una reflexión sobre las actitudes profesionales y pedagógicas que los docentes muestran en el proceso de didáctico. También se está tratando de entender cómo se ha llevado a cabo el proceso de enseñanza/aprendizaje en la educación superior hoy día. En ciertos casos, es más fácil de observar el proceso de orientación en las tapas educativas iniciales que en la educación superior.

Para Cunha et al. (2006), para el desarrollo de su trabajo, el orientador debe ser un investigador constante, y debe anticipar el conocimiento al grupo de docentes, leyendo mucho, no sólo sobre el contenido específico, sino también libros y diferente periódicos y revistas. El cumplimiento de las tareas que se relacionan con el trabajo del orientador, puede ayudar en el desarrollo y ejecución del proyecto de la institucion, proporcionar orientación sobre cuestiones pedagógicas y actuar principalmente en la formación continua de los profesores.

El orientador hace que la aplicación de la teoría en la práctica educativa se refleje en el trabajo en el aula, en el estudio y en el apoyo de las teorías docentes de los profesores.

"A medida que analizamos la enseñanza superior, es evidente la necesidad de una formación pedagógica-orientadora de los profesores universitarios. Esta capacitación que hace hincapié no sólo los métodos de enseñanza, sino también la incorporación de conceptos sobre el papel del docente en relación con el estudiante, la escuela y la sociedad misma" (Gil, 2005: 17).

Ante este panorama, Alonso et al. (2013:163) indica que necesitamos personas y profesionales, tutores EEES (TEEES)", formados y convencidos de superar los rasgos que nos configuran como seres de este siglo (incertidumbre, complejidad y antagonismo) y de procesos educativos (vivos, críticos, transformadores, solidarios, creativos) que puedan aportar formas diversas de abordaje. Estos TEEES, mediante su labor orientadora, han de constituir la esencia de lo humano, que tiene que desplegarse socialmente y dar sentido de nuevo a todo, en este mundo de estrés social y estrés evolutivo.

Hasta cierto punto, es común observar que los docentes trabajen de forma independiente y aislada, sin embargo, la ausencia de una planificación en la educación superior, de alguna manera refleja negativamente la falta de competencias en la formación inicial del profesorado universitario. También se observa negativamente las instituciones que no hacen orientación en la educación superior, con seguimiento de la enseñanza y el proceso de aprendizaje, por lo que es difícil darse cuenta de las realidades que se producen en el aula y entorece el desarrollo de la enseñanza de las competencias de los estudiantes en la formación docente. 


\section{Objetivos de la Investigación}

- Analizar la influencia de la profesionalizacion de la docencia universitaria en el desarrollo de competencias docentes de los estudiantes de educación en el Instituto Superior de Ciencias de la Educación (CINE) de Benguela.

- Diagnosticar el perfil académico y profesional de los profesores de la institución referida;

- Describir la influencia de la profesionalizacion de la docencia universitaria en el desarrollo de competencias docentes de los estudiantes de educación;

- Caracterizar los procedimientos metodológicos utilizados por los profesores para desarrollar las competencias docentes de los estudiantes en la formación del profesorado;

- Describir la influencia de la orientación pedagógica en la profesionalizacion de la docencia universitaria teniendo en cuenta el desarrollo de las competencias docentes de los estudiantes en la formación del profesorado;

- Definir el perfil de entrada y salida de los estudiantes de formación inicial en la CINE Benguela.

\section{Metodología de la Investigación}

El estudio constituye un elemento clave que resulta de la constatacion de la realidad objetiva del proceso de enseñanza-aprendizaje en curso en el Instituto Superior de Ciencias de la Educación de Benguela como supuesto de la mejora de las actividades educativas llevadas a cabo en la institución con el fin de retomar la calidad teniendo en cuenta los objetivos propuestos.

Para la investigación se determinó una población compuesta por profesores, estudiantes y miembros de la dirección de la CINE de Benguela, mediante un enfoque cuantitativo y cualitativo, basado en cuestionarios y entrevistas. De este modo, la muestra esta seleccionada, por muestreo aleatorio simple, de 50 profesores y 100 alumnos, e intencionalmente formados por tres miembros de la dirección.

En cuanto a los cuestionarios y entrevistas, su desarrollo siguió cuatro subescalas construidas sobre el tema en cuestión:

1. Los procedimientos metodológicos, pedagógicos y estilo de enseñanza;

2. La orientación del proceso de enseñanza/aprendizaje;

3. La profesionalizacion de la formacion docente universitaria en CINE de Benguela;

4. El perfil de entrada de los estudiantes en la CINE de Benguela. 
Algunos de los resultados más relevantes que se obtuvieron tras la puesta en marcha de estas técnicas de análisis podremos verlos en el siguiente apartado.

\section{Resultados}

El primer paso en el proceso de análisis de los datos recogidos en esta investigación, tras el correspondiente escrutinio y recuento de frecuencias de respuesta, requiere la observación detenida, en la tabla siguiente, de las medias aritméticas obtenidas, así como de sus correspondientes desviaciones típicas.

En esta ocasión se presentan algunos de los resultados que se han obtenido a partir de la recopilación de datos de los maestros, estudiantes y miembros de la entidad.

Grafico 1. Ralacion tiempo laboral y contenidos

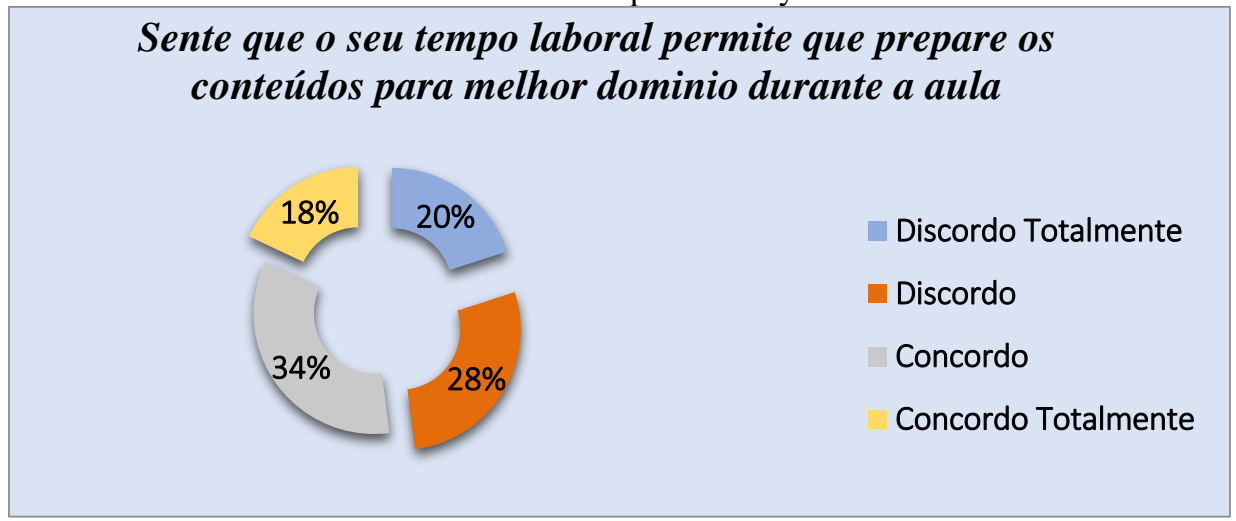

Fuente: elaboraion propia.

Con respecto a los estudantes participan activamente, se muestra que el 54\% de los docentes participantes opinan estar de acuerdo, así mismo el 28\% está totalmente de acuerdo, esto supone el $82 \%$ de la totalidad de la muestra. No existe porcentaje en el grado de total desacuerdo. Sobre esta materia, la mayoría considera que los Profesores han requerido tiempo para planificar las lecciones, que se refleja en el enfoque de los contenidos que se enseñan en el aula.

Table 1. Pruebas de chi-cuadrado

\begin{tabular}{|c|r|r|r|}
\hline & Valor & gl & \multicolumn{2}{|c|}{$\begin{array}{c}\text { Sig. asintótica } \\
\text { (bilateral) }\end{array}$} \\
\hline Chi-cuadrado de Pearson & $38,116^{\mathrm{a}}$ & 2 &, 000 \\
Razón de verosimilitudes & 45,267 & 2 &, 000 \\
Asociación lineal por lineal & 29,365 & 1 &, 000 \\
N de casos válidos & 50 & & \\
\hline
\end{tabular}

a. 2 casillas (33,3\%) tienen una frecuencia esperada inferior a 5. La frecuencia mínima esperada es 3,06.

Fuente: elabracion propia 


\section{Análisis De Variables Categóricas: Tablas De Contingencia}

En este apartado se muestran las tablas de contingencia referentes a los cruces que se han realizado entre las variables, en función de los objetivos de la investigación y con sus correspondientes estadísticos descriptivos. Se han elegido para este análisis las pruebas de chi-cuadrado, manifestadas con el respectivo grado de libertad (gl) y la significancia asintótica. El nivel de confianza con el que se ha trabajado ha sido del 95\% (valor de $\alpha 0.05$ ).

\section{Género - Perfil}

En relación al género, se encuentran diferencias estadísticamente significativas (sig.asintótica 0,000), atendiendo a los licenciados, el 93, 9\% de los hombres pertenecen a este grupo, representando el $100 \%$ de este grado académico, sin existir mujeres licenciadas. El 6,1\% de los hombres son Mestres, ningún doctor. En el caso de las mujeres, aparte de lo anteriormente mencionado, nos encontramos con que el 85,7\% de los componentes del grupo de Mestres son mujeres. Es destacable que dentro del grupo de doctores sólo haya representación femenina, siendo del 100\%, respecto al total de mujeres esto supone el 29,4\%.

Tabla 2. Pruebas de chi-cuadrado

\begin{tabular}{|c|r|r|r|}
\hline & Valor & gl & $\begin{array}{c}\text { Sig. asintótica } \\
\text { (bilateral) }\end{array}$ \\
\hline Chi-cuadrado de Pearson & $42,361^{\mathrm{a}}$ & 2 &, 000 \\
Razón de verosimilitudes & 52,620 & 2 &, 000 \\
Asociación lineal por lineal & 37,212 & 1 &, 000 \\
N de casos válidos & 50 & & \\
\hline
\end{tabular}

a. 3 casillas (50,0\%) tienen una frecuencia esperada inferior a 5. La frecuencia mínima esperada es 1,70 .

Fuente: elaboracion propia.

Tabla 3. Genero y grado académico.

Tabela de Contingência Género^ ${ }^{\wedge}$ Grau académico

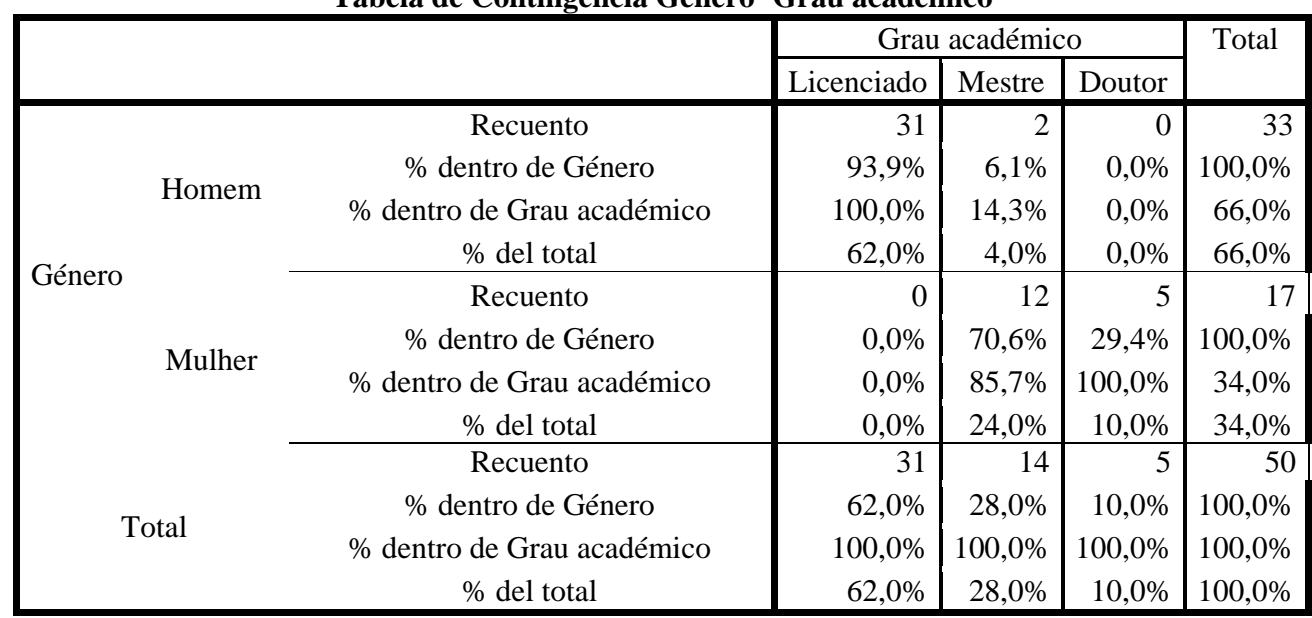

Fuente: elaboracion propia. 
El siguiente cruce en el que se han dado diferencias estadísticamente significativas (significancia asintótica, 000) es el realizado entre el género y Departamento de Ensino e Investigação a que pertence.

Tabla 4. Chi cuadrado

Pruebas de chi-cuadrado

\begin{tabular}{|c|r|r|r|}
\hline & Valor & gl & \multicolumn{2}{|c|}{$\begin{array}{c}\text { Sig. asintótica } \\
\text { (bilateral) }\end{array}$} \\
\hline Chi-cuadrado de Pearson & $40,642^{\mathrm{a}}$ & 4 &, 000 \\
Razón de verosimilitudes & 51,886 & 4 &, 000 \\
Asociación lineal por lineal & 31,540 & 1 &, 000 \\
N de casos válidos & 50 & & \\
\hline
\end{tabular}

a. 5 casillas $(50,0 \%)$ tienen una frecuencia esperada inferior a 5. La frecuencia mínima esperada es 3,06.

Fuente: elaboracion propia

En la tabela de contingência que se expone se puede ver que el departamento de Ciencias de la Educación está compuesto por un 100\% de hombres, dentro del total masculino representan el 27,3\%. Lo mismo ocurre en departamentos como Ciencias Exactas y Ciencias Sociales, representado únicamente por profesorado de género masculino. En relación a Ciencias de la Naturaleza el $30 \%$ son profesores y el $70 \%$ son mujeres. Por último, en el departamento de Letras Modernas, sólo existe representación femenina, el $100 \%$ son profesoras.

Análisis Factorial I: perfil personal y profesional (A) y dados sobre o instituto superior de ciencias de la educacion de Benguela (B).

Se presentan los resultados obtenidos una vez realizado el test de esfericidad de Barlett, revelando un chi-cuadrado aproximado a 961,777, con gl 66 significativo al 0,000; el índice de KMO de Káiser- Mayer- Olkin es de ,909. Estos resultados nos han llevado a ejecutar el análisis factorial, eligiendo el método de Análisis de Componentes Principales (PCA), con rotación de variables, procedimiento Varimax con Kaiser. Los resultados obtenidos se muestran a continuación:

Tabla 5. KMO y prueba de Bartlett

KMO y prueba de Bartlett

\begin{tabular}{|c|r|r|}
\hline \multicolumn{2}{|c|}{ Medida de adecuación muestral de Kaiser-Meyer-Olkin. } &, 909 \\
& Chi-cuadrado aproximado & 961,777 \\
Prueba de esfericidad de Bartlett & gl & 66 \\
& Sig. &, 000 \\
\hline
\end{tabular}

Fuente: elaboracion propia.

A continuación, observamos la tabla de comunalidades, se aprecian una serie de variables con un mayor porcentaje: gráu académico (92,4\%\%), Departamento de Ensino e Investigação a que pertence (95,8\%), Ano (s) 
curricular que leciona (91,1\%), nível sócio-económico dos estudantes (93,9\%), y Faixa etária dos estudantes por turma (95,8\%).

Tabla 6. Datos de identificacion

Comunalidades

\begin{tabular}{|c|c|c|}
\hline & Inicial & Extracción \\
\hline Idade & 1,000 & ,777 \\
\hline Género & 1,000 & 887 \\
\hline Grau académico & 1,000 & 924 \\
\hline $\begin{array}{l}\text { Departamento de Ensino e } \\
\text { Investigação a que pertence }\end{array}$ & 1,000 & 958 \\
\hline $\begin{array}{c}\text { Outras funções no ISCED de } \\
\text { Benguela }\end{array}$ & 1,000 & 853 \\
\hline $\begin{array}{c}\text { Tempo de serviço como docente } \\
\text { universitário }\end{array}$ & 1,000 & 884 \\
\hline $\begin{array}{c}\text { Número de disciplinas (s) que } \\
\text { lecciona }\end{array}$ & 1,000 & 880 \\
\hline Ano (s) curricular que leciona & 1,000 & 911 \\
\hline $\begin{array}{c}\text { Período (s) que lecciona (Manhã, } \\
\text { tarde e Noite) }\end{array}$ & 1,000 & 791 \\
\hline $\begin{array}{c}\text { Nível sócio-económico dos } \\
\text { estudantes }\end{array}$ & 1,000 & 939 \\
\hline Número de estudantes por turma & 1,000 & 821 \\
\hline $\begin{array}{l}\text { Faixa etária dos estudantes por } \\
\text { turma }\end{array}$ & 1,000 & 958 \\
\hline
\end{tabular}

Método de extracción: Análisis de Componentes principales. 
Matriz de correlaciones

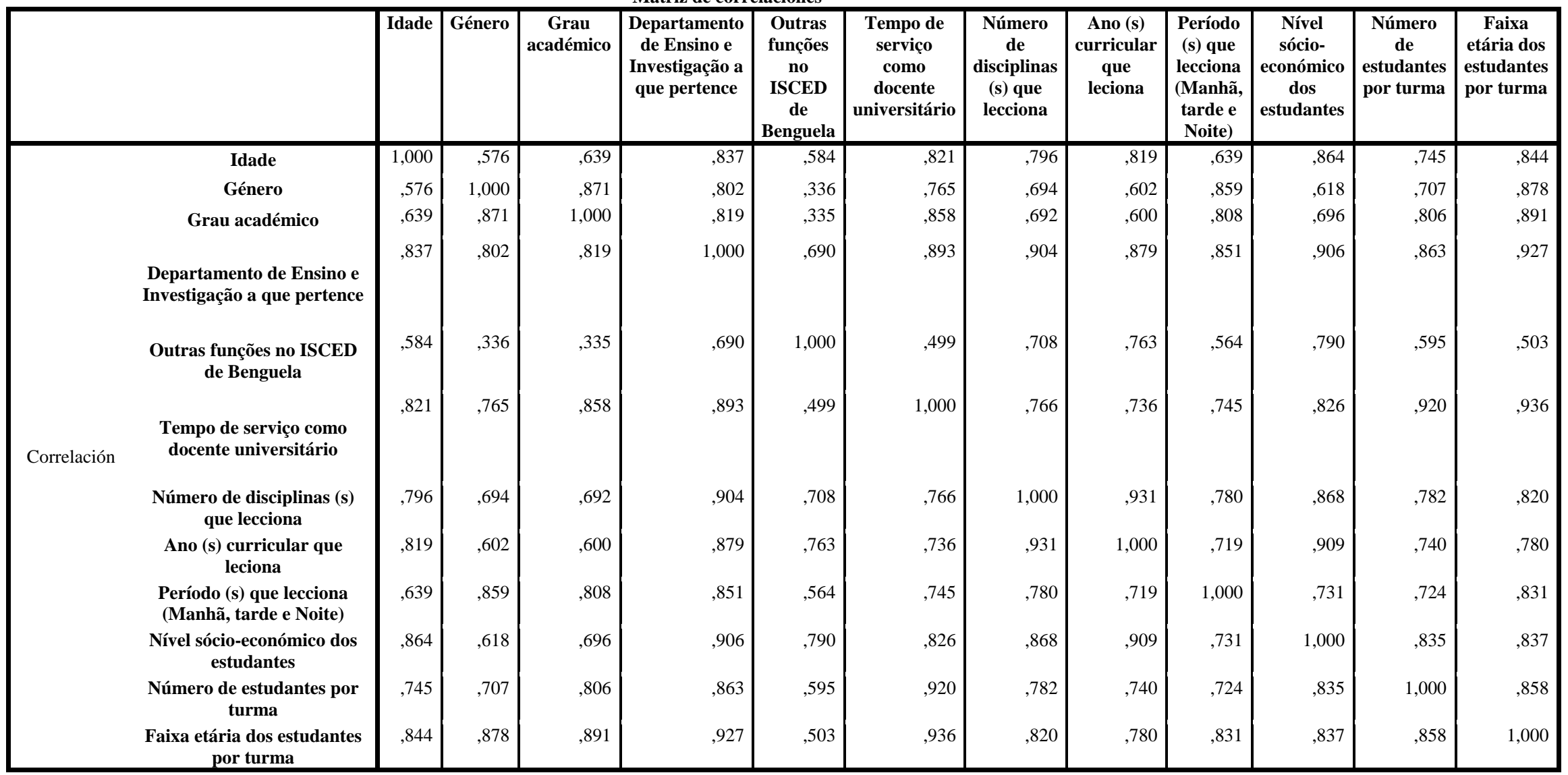

Fuente: elaboracion propia. 
Se muestra en la tabla anterior la matriz de correlaciones de Pearson por la que hemos comenzado para realizar el análisis de factores con el método de extracción de componentes principales.

En la tabla de varianza total explicada, siguiendo el método de extracción de componentes principales, se explica la variabilidad total por cada componente y por la que se explica cada uno de ellos. Nos encontramos con los dos factores que explican la dimensión analizada, de las 12 variables existentes, con un 88,179\% total de la varianza, porcentaje que podemos considerar como bueno.

Tabla 7. Varianza total explicada.

Varianza total explicada

\begin{tabular}{|c|c|c|c|c|c|c|c|c|c|}
\hline \multirow[t]{2}{*}{$\begin{array}{c}\text { Compone } \\
\text { nte }\end{array}$} & \multicolumn{3}{|c|}{ Autovalores iniciales } & \multicolumn{3}{|c|}{$\begin{array}{c}\text { Sumas de las } \\
\text { saturaciones al cuadrado } \\
\text { de la extracción } \\
\end{array}$} & \multicolumn{3}{|c|}{$\begin{array}{c}\text { Suma de las } \\
\text { saturaciones al cuadrado } \\
\text { de la rotación } \\
\end{array}$} \\
\hline & $\begin{array}{c}\text { Tota } \\
\text { l }\end{array}$ & $\begin{array}{c}\% \text { de } \\
\text { la } \\
\text { varian } \\
\text { za }\end{array}$ & $\begin{array}{c}\% \\
\text { acumula } \\
\text { do }\end{array}$ & $\begin{array}{c}\text { Tota } \\
\text { l }\end{array}$ & $\begin{array}{l}\% \text { de } \\
\text { la } \\
\text { varian } \\
\text { za }\end{array}$ & $\begin{array}{c}\% \\
\text { acumula } \\
\text { do }\end{array}$ & $\begin{array}{c}\text { Tota } \\
\text { l }\end{array}$ & $\begin{array}{l}\% \text { de } \\
\text { la } \\
\text { varian } \\
\text { za }\end{array}$ & $\begin{array}{c}\% \\
\text { acumula } \\
\text { do }\end{array}$ \\
\hline 1 & $\begin{array}{r}9,43 \\
1\end{array}$ & 78,588 & 78,588 & $\begin{array}{r}9,43 \\
1\end{array}$ & 78,588 & 78,588 & $\begin{array}{r}5,74 \\
8\end{array}$ & 47,903 & 47,903 \\
\hline 2 & $\begin{array}{r}1,15 \\
1\end{array}$ & 9,591 & 88,179 & $\begin{array}{r}1,15 \\
1\end{array}$ & 9,591 & 88,179 & $\begin{array}{r}4,83 \\
3\end{array}$ & 40,276 & 88,179 \\
\hline 3 & ,494 & 4,120 & 92,299 & & & & & & \\
\hline 4 & 315 & 2,628 & 94,928 & & & & & & \\
\hline 5 & 179 & 1,492 & 96,419 & & & & & & \\
\hline 6 & 108, & 899, & 97,318 & & & & & & \\
\hline 7 & 103 & ,859 & 98,177 & & & & & & \\
\hline 8 & 068, & ,569 & 98,746 & & & & & & \\
\hline 9 & ,059 & ,491 & 99,237 & & & & & & \\
\hline 10 & 039, & ,322 & 99,558 & & & & & & \\
\hline 11 & ,032 & ,270 & 99,828 & & & & & & \\
\hline 12 & 021 & ,172 & 100,000 & & & & & & \\
\hline
\end{tabular}

Método de extracción: Análisis de Componentes principales.

Fuente: elaboracion propia.

De manera gráfica, podemos observar estos resultados a través del Gráfico de Sedimentación de Cattel, mostrándose los autovalores y según el número de componente. Esto facilita establecer el número óptimo de factores que deben estar presentes, todos ellos con un valor mayor que 1 ( 2 factores). 
Grafico 2. Sedimentación

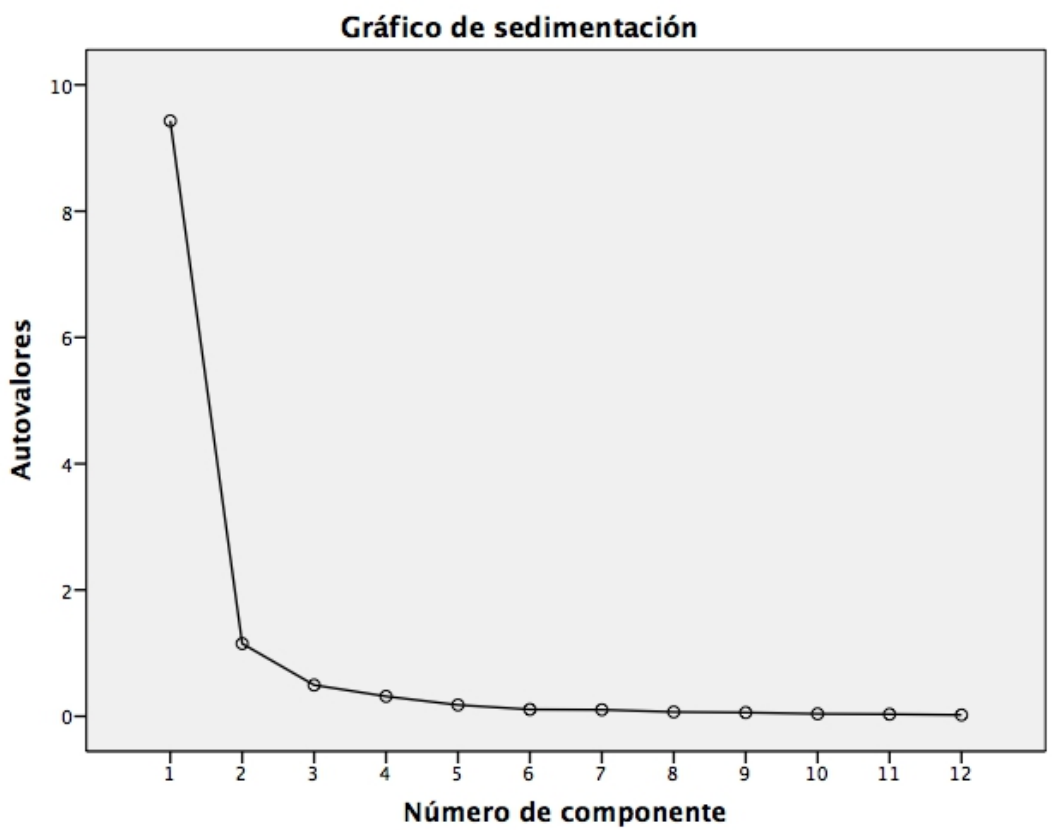

Fuente: elaboracion propia.

Para finalizar, se incluyen las tablas de resultados del análisis factorial, lo que se indica es lo que cada variable aporta al factor. Esto quiere decir que cada factor se formará a partir de las variables que más aportación tienen hacia él, para esta descripción nos basaremos en aquellas variables que supongan 0,4 o más a cada factor $\pm 0,4$.

Tabla 8. Componentes

Matriz de componentes ${ }^{\mathrm{a}}$

\begin{tabular}{|c|c|c|}
\hline & \multicolumn{2}{|c|}{ Componente } \\
\cline { 2 - 3 } Idade & \multicolumn{1}{|c|}{2} \\
\hline Género &, 866 &, 165 \\
Grau académico &, 823 &,- 457 \\
Departamento de Ensino e Investigação a que pertence &, 854 &,- 442 \\
Outras funções no ISCED de Benguela &, 024 \\
Tempo de serviço como docente universitário &, 686 &, 619 \\
Número de disciplinas (s) que lecciona &, 924 &,- 172 \\
Ano (s) curricular que leciona &, 918 &, 194 \\
Período (s) que lecciona (Manhã, tarde e Noite) &, 892 &, 339 \\
Nível sócio-económico dos estudantes &, 930 &,- 180 \\
Número de estudantes por turma &, 271 \\
Faixa etária dos estudantes por turma &, 904 &,- 058 \\
Mén &, 956 &,- 211 \\
\hline
\end{tabular}

Método de extracción: Análisis de componentes principales.

a. 2 componentes extraídos

Fuente: elaboracion propia. 
En este caso, debido a la pertenencia de las variables en ambos factores, hemos elegido aquellos que aportan más a cada factor.

Tabla 9. Componentes rotados.

Matriz de componentes rotados ${ }^{\mathrm{a}}$

\begin{tabular}{|c|c|c|}
\hline & \multicolumn{2}{|c|}{ Componente } \\
\hline & 1 & 2 \\
\hline Idade & ,535 & ,700 \\
\hline Género & 918 & ,208 \\
\hline Grau académico & ,931 & 240 \\
\hline Departamento de Ensino e Investigação a que pertence & ,713 & 670 \\
\hline Outras funções no ISCED de Benguela & 099 & ,918 \\
\hline Tempo de serviço como docente universitário & ,803 & ,488 \\
\hline Número de disciplinas (s) que lecciona & ,555 & ,756 \\
\hline Ano (s) curricular que leciona & 438 & ,848 \\
\hline Período (s) que lecciona (Manhã, tarde e Noite) & ,769 & ,447 \\
\hline Nível sócio-económico dos estudantes &, 512 & 822 \\
\hline Número de estudantes por turma & ,712 & ,560 \\
\hline Faixa etária dos estudantes por turma & 853 & ,480 \\
\hline
\end{tabular}

Método de extracción: Análisis de componentes principales.

Método de rotación: Normalización Varimax con Kaiser.

a. La rotación ha convergido en 3 iteraciones.

Fuente: elaboracion propia.

A partir de los anteriormente descrito, se realiza la siguiente interpretación:

Factor 1: formado por variables como género, grado académico, Departamento de Educación e Investigación a la que pertenece, el tiempo de servicio como profesor universitario, y tiempo (mañana, tarde y noche), el número de alumnos por clase, rango de edad de los estudiantes por clase. Este factor podría ser denominado como profesional de estado y los Estudiantes del Centro perfil.

Factor 2: compuesto por variables tales como la edad, otras funciones en la CINE Benguela, número de disciplinas (s) que enseña, el nivel socioeconómico de los estudiantes.Denominamos a este factor como características de la propia docencia.

Análisis Factorial II: Dimensión 1. Profesionalización del docente universitario.

Se realiza el mismo procedimiento que en anterior epígrafe. Las pruebas de esfericidad de Barlett nos proporciona un valor de chi-cuadrado aproximado 1310,942, un gl de 91 significativo al 0,000; a su vez el índice de Kaiser-Meyer-Olkin de adecuación de nuestros es de ,932. 
Tabla 10. KMO y prueba de Bartlett

KMO y prueba de Bartlett

Medida de adecuación muestral de Kaiser-Meyer-Olkin.

Chi-cuadrado aproximado

\begin{tabular}{|c|c|c|}
\hline Medida de adecuación mu & $\begin{array}{l}\text { le Kaiser-Meyer-Olkin. } \\
\text { Chi-cuadrado aproximado }\end{array}$ & $\begin{array}{r}, 932 \\
1310,942\end{array}$ \\
\hline Prueba de esfericidad de Bartlett & $\begin{array}{l}\text { gl } \\
\text { Sig. }\end{array}$ & $\begin{array}{r}91 \\
, 000\end{array}$ \\
\hline
\end{tabular}

Fuente: elaboracion propia.

Las variables con un mayor porcentaje quedan representadas en la tabla de comunalidades vista a continuación:

Tabla 11. Comunes

\section{Comunalidades}

\begin{tabular}{|c|c|c|}
\hline & & ón \\
\hline $\begin{array}{l}\text { n aulas revela uma atitude pedagógica que favorece o } \\
\text { senvolvimento das competências profissionais dos estudantes; }\end{array}$ & 000 & \\
\hline $\begin{array}{l}\text { sua motivação profissional favorece a formação de competências } \\
\text { s estudantes; }\end{array}$ & 000 & ,701 \\
\hline sistemático e combinado de métodos ativos durante as aulas; & 1,000 & ,89 \\
\hline $\begin{array}{l}\text { esenta e partilha o programa de disciplina com os estudantes no } \\
\text { o do ano lectivo; }\end{array}$ & 1,000 & ,877 \\
\hline $\begin{array}{l}\text { po laboral permite que prepare os conteúdos para } \\
\text { inte a aula; }\end{array}$ & 1,000 & ,921 \\
\hline participam activamente; & 1,000 & 846 \\
\hline $\begin{array}{l}\text { s incentivam os estudantes à pesquisa científica e ao } \\
0 \text {; }\end{array}$ & 1,000 & 858, \\
\hline $\begin{array}{l}\text { acidade de análise e interpretação dos estudantes favorece o } \\
\text { envolvimento das suas competências pedagógicas; }\end{array}$ & 1,000 & ,926 \\
\hline $\begin{array}{l}\text { instituição possui condições que favorecem o desenvolvimento das } \\
\text { ompetências pedagógicas (salas de aulas, biblioteca e meios } \\
\text { formáticos); }\end{array}$ & 1,000 & ,9 \\
\hline $\begin{array}{l}\text { Os estudantes envolvem-se voluntariamente na busca de } \\
\text { conhecimentos. }\end{array}$ & 1,000 & 873 \\
\hline $\begin{array}{l}\text { perfil e a deontologia profissional dos docentes favorecem o } \\
\text { senvolvimento de competências pedagógicas dos estudantes; }\end{array}$ & 1,000 & ,894 \\
\hline $\begin{array}{l}\text { ssores participam massivamente em eventos metodológicos e } \\
\text { s; }\end{array}$ & 1,000 & ,926 \\
\hline & & \\
\hline docentes carecem de sessões de capacitação pedagógica em cada & 1,000 & ,847 \\
\hline
\end{tabular}

Método de extracción: Análisis de Componentes principales.

Fuente: elaboracion propia.

A partir de la tabla de la varianza total explicada mostrada seguidamente, se ve que, a partir del método de extracción de componentes principales, es posible explicar la variabilidad total por cada componente. Son dos factores, de los 14, los que pueden explicar la primera dimensión del cuestionario construido para el estudio, con una varianza total de $87,615 \%$, un porcentaje muy bueno. 
Tabla 12. varianza total explicada

Varianza total explicada

\begin{tabular}{|c|r|r|r|r|r|r|}
\hline Componente & \multicolumn{3}{|c|}{ Autovalores iniciales } & \multicolumn{3}{c|}{ Sumas de las saturaciones al cuadrado de la } \\
& \multicolumn{1}{|c|}{ extracción } & \\
\cline { 2 - 7 } & Total & $\begin{array}{c}\text { \% de la } \\
\text { varianza }\end{array}$ & $\begin{array}{c}\text { \% } \\
\text { acumulado }\end{array}$ & Total & \% de la varianza & \% acumulado \\
\hline $\mathbf{1}$ & $\mathbf{1 2 , 2 6 6}$ & $\mathbf{8 7 , 6 1 5}$ & $\mathbf{8 7 , 6 1 5}$ & $\mathbf{1 2 , 2 6 6}$ & $\mathbf{8 7 , 6 1 5}$ & $\mathbf{8 7 , 6 1 5}$ \\
2 &, 430 & 3,070 & 90,685 & & & \\
3 &, 376 & 2,684 & 93,369 & & & \\
4 &, 250 & 1,784 & 95,152 & & & \\
5 &, 156 & 1,111 & 96,263 & & & \\
6 &, 122 &, 874 & 97,137 & & & \\
7 &, 118 &, 845 & 97,982 & & & \\
8 &, 080 &, 574 & 98,556 & & & \\
9 &, 055 &, 393 & 98,949 & & & \\
10 &, 045 &, 321 & 99,269 & & & \\
11 &, 034 &, 243 & 99,512 & & & \\
12 &, 028 &, 203 & 99,715 & & & \\
13 &, 024 &, 170 & 99,885 & & & \\
14 &, 016 &, 115 & 100,000 & & & \\
\hline
\end{tabular}

Método de extracción: Análisis de Componentes principales.

Fuente: elaboracion propia.

En este caso no se ha podido realizar la rotación de componentes, ya que al haberse extraído sólo un factor, todas las variables pertenecen a dicha dimensión:

Tabla 13. Matriz de componentes.

Matriz de componentes ${ }^{\mathrm{a}}$

\begin{tabular}{|c|c|}
\hline & $\begin{array}{c}\text { Componente } \\
1\end{array}$ \\
\hline $\begin{array}{l}\text { Em aulas revela uma atitude pedagógica que favorece o desenvolvimento das } \\
\text { competências profissionais dos estudantes; } \\
\text { A sua motivação profissional favorece a formação de competências dos estudantes; } \\
\text { Usa sistemático e combinado de métodos ativos durante as aulas; } \\
\text { Apresenta e partilha o programa de disciplina com os estudantes no início do ano } \\
\text { lectivo; } \\
\text { Sente que o seu tempo laboral permite que prepare os conteúdos para melhor domínio } \\
\text { durante a aula; } \\
\text { Os estudantes durante as aulas participam activamente; } \\
\text { Os professores incentivam os estudantes à pesquisa científica e ao estudo de grupo; } \\
\text { Capacidade de análise e interpretação dos estudantes favorece o desenvolvimento das } \\
\text { suas competências pedagógicas; } \\
\text { A instituição possui condições que favorecem o desenvolvimento das competências } \\
\text { pedagógicas (salas de aulas, biblioteca e meios informáticos); } \\
\text { Os estudantes envolvem-se voluntariamente na busca de conhecimentos; } \\
\text { O perfil e a deontologia profissional dos docentes favorecem o desenvolvimento de } \\
\text { competências pedagógicas dos estudantes; } \\
\text { Os professores participam massivamente em eventos metodológicos e científicos; } \\
\text { A carga docente é favorável ao processo de ensino-aprendizagem; } \\
\text { Os docentes carecem de sessões de capacitação pedagógica em cada princípio do ano } \\
\text { académico. }\end{array}$ & 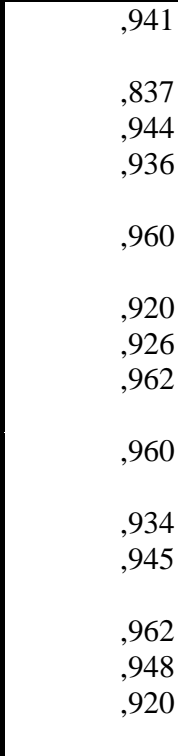 \\
\hline
\end{tabular}

Método de extracción: Análisis de componentes principales.

a. 1 componentes extraídos

Fuente: elaboracion propia. 


\section{Análisis Factorial III: Dimensión 2. Control de la enseñanza / aprendizaje.}

En este tercer apartado, analizamos e interpretamos los resultados obtenidos una vez realizado el test de esfericidad de Barlett, se alcanza un valor de chi-cuadrado aproximado de 1050,269; gl 78 significativo a 0,000 y con un índice KMO de ,882.

Tabla 14. KMO y prueba de Bartlett

KMO y prueba de Bartlett

\begin{tabular}{|c|c|c|}
\hline Medida de adecuación mu & $\begin{array}{l}\text { le Kaiser-Meyer-Olkin. } \\
\text { Chi-cuadrado aproximado }\end{array}$ & $\begin{array}{r}, 882 \\
1050,269\end{array}$ \\
\hline Prueba de esfericidad de Bartlett & gl & 78 \\
\hline & Sig. & 000 \\
\hline
\end{tabular}

Fuente: elaboración propia.

A continuación se exponen los valores de extracción en la tabla de comunalidades, seleccionamos las que superan el $90 \%$ ya que todas están por encima del $80 \%$, se ponen en negrita los valores mencionadas anteriormente.

Tabla 15. Comunes

Comunalidades

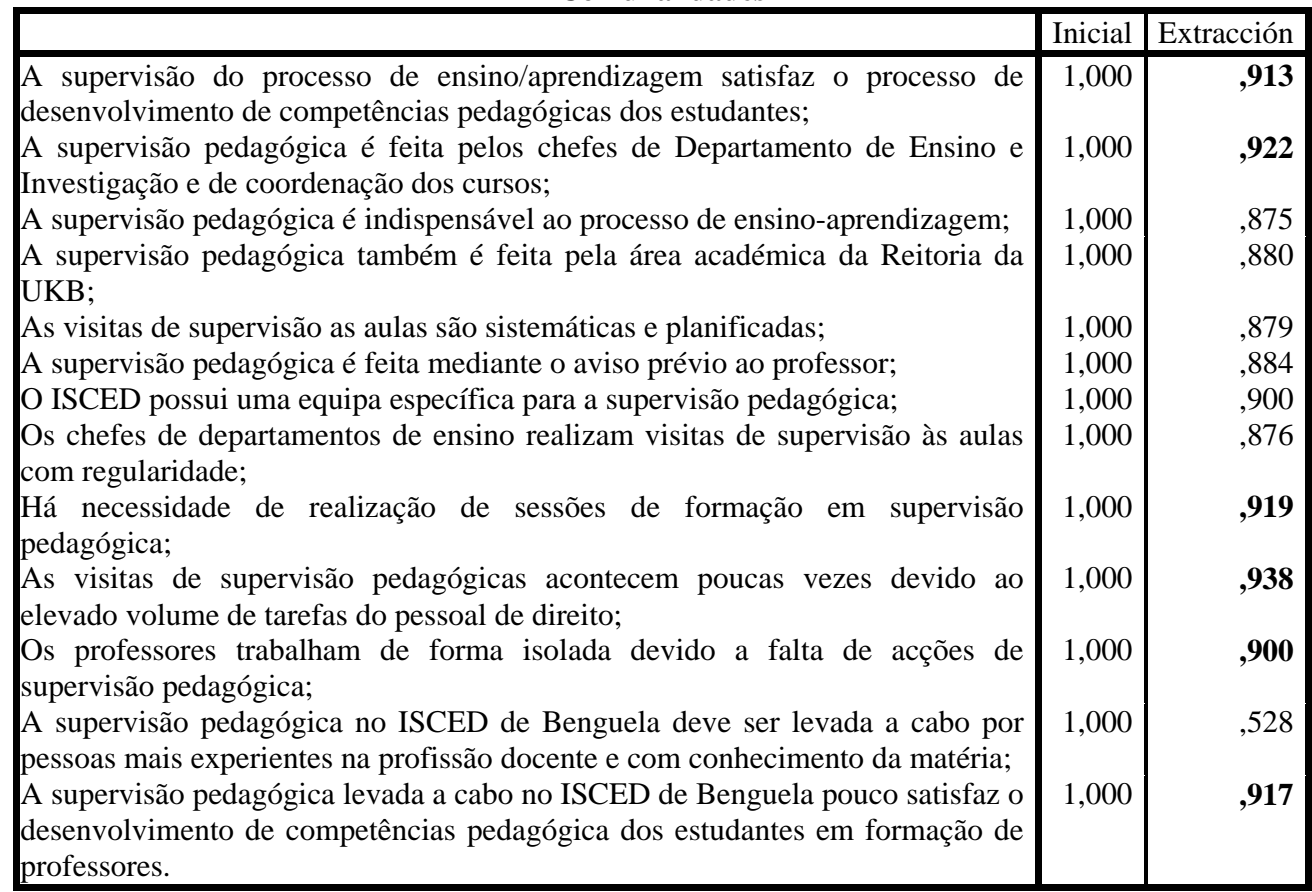

Método de extracción: Análisis de Componentes principales.

Fuente: elaboración propia.

A continuación, se exhibe la matriz de correlaciones de la dimensión. 
Tabla 16. Correlaciones

Matriz de correlaciones

\begin{tabular}{|c|c|c|c|c|c|c|c|c|c|c|c|c|c|}
\hline & 2.1 & 2.2 & 2.3 & 2.4 & 2.5 & 2.6 & 2.7 & 2.8 & 2.9 & 2.10 & 2.11 & 2.12 & 2.13 \\
\hline $\begin{array}{l}\text { A supervisão do processo de ensino/aprendizagem satisfaz o } \\
\text { processo de desenvolvimento de competências pedagógicas dos } \\
\text { estudantes; }\end{array}$ & 1,000 & 903 & ,510 & 875 & ,872 & ,821 & ,863 & ,861 & ,716 & 903 & ,831 & ,250 & ,750 \\
\hline $\begin{array}{l}\text { A supervisão pedagógica é feita pelos chefes de Departamento de } \\
\text { Ensino e Investigação e de coordenação dos cursos; }\end{array}$ & ,903 & 1,000 & ,420 & ,795 & 919, & 847 & 876 & 859 & ,704 & 938, & ,784 & ,206 & ,716 \\
\hline $\begin{array}{l}\text { A supervisão pedagógica é indispensável ao processo de ensino- } \\
\text { aprendizagem; }\end{array}$ & ,510 & ,420 & 1,000 & ,725 & ,392 & ,320 & ,297 & 281 & 813 & ,448 & ,720 & ,622 & ,795 \\
\hline $\begin{array}{l}\text { A supervisão pedagógica também é feita pela área académica da } \\
\text { Reitoria da UKB; }\end{array}$ & ,875 & ,795 & ,725 & 1,000 & ,758 & 643 & ,664 & ,616 & 881 & ,822 & 917 & ,356 & ,869 \\
\hline As visitas de supervisão as aulas são sistemáticas e planificadas; & ,872 & 919 & ,392 & ,758 & 1,000 & ,842 & ,837 & ,831 & ,657 & 900 & ,763 & 192 & ,722 \\
\hline $\begin{array}{l}\text { A supervisão pedagógica é feita mediante o aviso prévio ao } \\
\text { professor; }\end{array}$ & ,821 & ,847 & ,320 & ,643 & ,842 & 1,000 & ,911 & ,912 & ,536 & ,890 & ,708 & ,157 & ,609 \\
\hline $\begin{array}{l}\text { O ISCED possui uma equipa específica para a supervisão } \\
\text { pedagógica; }\end{array}$ & ,863 & ,876 & ,297 & ,664 & ,837 & 911 & 1,000 & 896 & 499 & 892 & 658 & ,146 & ,566 \\
\hline $\begin{array}{l}\text { Os chefes de departamentos de ensino realizam visitas de } \\
\text { supervisão às aulas com regularidade; }\end{array}$ & ,861 & 859 & 281 & 616 & 831 & 912 & 896 & 1,000 & ,471 & 819 & ,622 & 138 & ,535 \\
\hline $\begin{array}{l}\text { Há necessidade de realização de sessões de formação em } \\
\text { supervisão pedagógica; }\end{array}$ & ,716 & ,704 & 813 & 881 & 657 & ,536 & 499 & ,471 & 1,000 & ,731 & 908 & ,467 & 963 \\
\hline $\begin{array}{l}\text { As visitas de supervisão pedagógicas acontecem poucas vezes } \\
\text { devido ao elevado volume de tarefas do pessoal de direito; }\end{array}$ & 903 & 938 & ,448 & 822 & ,900 & 890 & ,892 & 819, & ,731 & 1,000 & 840 & ,220 & ,756 \\
\hline $\begin{array}{l}\text { Os professores trabalham de forma isolada devido a falta de acções } \\
\text { de supervisão pedagógica; }\end{array}$ & 831 & ,784 & ,720 & 917 & ,763 & ,708 & 658 & ,622 & 908 & 840 & 1,000 & ,354 & 923 \\
\hline $\begin{array}{l}\text { A supervisão pedagógica no ISCED de Benguela deve ser levada a } \\
\text { cabo por pessoas mais experientes na profissão docente e com } \\
\text { conhecimento da matéria; }\end{array}$ & ,250 & ,206 & ,622 & 356 & 192, & 157, & ,146 & 138 & ,467 & ,220 & ,354 & 1,000 & ,460 \\
\hline $\begin{array}{l}\text { A supervisão pedagógica levada a cabo no ISCED de Benguela } \\
\text { pouco satisfaz o desenvolvimento de competências pedagógica dos } \\
\text { estudantes em formação de professores. }\end{array}$ & ,750 & ,716 & ,795 & ,869 & ,722 & 609 & ,566 & ,535 & 963 & ,756 & 923 & ,460 & 1,000 \\
\hline
\end{tabular}

Fuente: elaboración propia. 
Se muestra la tabla de varianza total explicada, en la que siguiendo el método de extracción de componentes principales, se explica la variabilidad total por cada componente y la que explica cada uno de ellos. Son dos los factores que explican la segunda dimensión del cuestionario, de las 13 variables existentes, con un $87,169 \%$ total de la varianza, porcentaje que podemos considerar como bastante bueno.

Tabla 17. Varianza tota expliacada

Varianza total explicada

\begin{tabular}{|c|c|c|c|c|c|c|c|c|c|}
\hline \multirow[t]{2}{*}{ Componente } & \multicolumn{3}{|c|}{ Autovalores iniciales } & \multicolumn{3}{|c|}{$\begin{array}{c}\text { Sumas de las saturaciones al } \\
\text { cuadrado de la extracción }\end{array}$} & \multicolumn{3}{|c|}{$\begin{array}{c}\text { Suma de las saturaciones al } \\
\text { cuadrado de la rotación }\end{array}$} \\
\hline & Total & $\begin{array}{c}\text { \% de la } \\
\text { varianza }\end{array}$ & $\begin{array}{c}\% \\
\text { acumulado }\end{array}$ & Total & $\begin{array}{c}\% \text { de la } \\
\text { varianza }\end{array}$ & $\begin{array}{c}\% \\
\text { acumulado }\end{array}$ & Total & $\begin{array}{l}\% \text { de la } \\
\text { varianza }\end{array}$ & $\begin{array}{c}\% \\
\text { acumulado }\end{array}$ \\
\hline 1 & 9,354 & 71,955 & 71,955 & 9,354 & 71,955 & 71,955 & 7,085 & 54,500 & 54,500 \\
\hline 2 & 1,978 & 15,214 & 87,169 & 1,978 & 15,214 & 87,169 & 4,247 & 32,670 & 87,169 \\
\hline 3 & 671 & 5,162 & 92,332 & & & & & & \\
\hline 4 & ,240 & 1,848 & 94,180 & & & & & & \\
\hline 5 & 207, & 1,591 & 95,770 & & & & & & \\
\hline 6 & 150 & 1,152 & 96,922 & & & & & & \\
\hline 7 & 115 & 883 & 97,804 & & & & & & \\
\hline 8 & ,095 & ,730 & 98,535 & & & & & & \\
\hline 9 & 072 & ,556 & 99,091 & & & & & & \\
\hline 10 & ,045 & 345 & 99,436 & & & & & & \\
\hline 11 & ,037 & ,283 & 99,719 & & & & & & \\
\hline 12 & 021 & 161 & 99,880 & & & & & & \\
\hline 13 & ,016 & ,120 & 100,000 & & & & & & \\
\hline
\end{tabular}

Método de extracción: Análisis de Componentes principales.

Fuente: elaboración propia.

Grafico 3. Sedimentacion

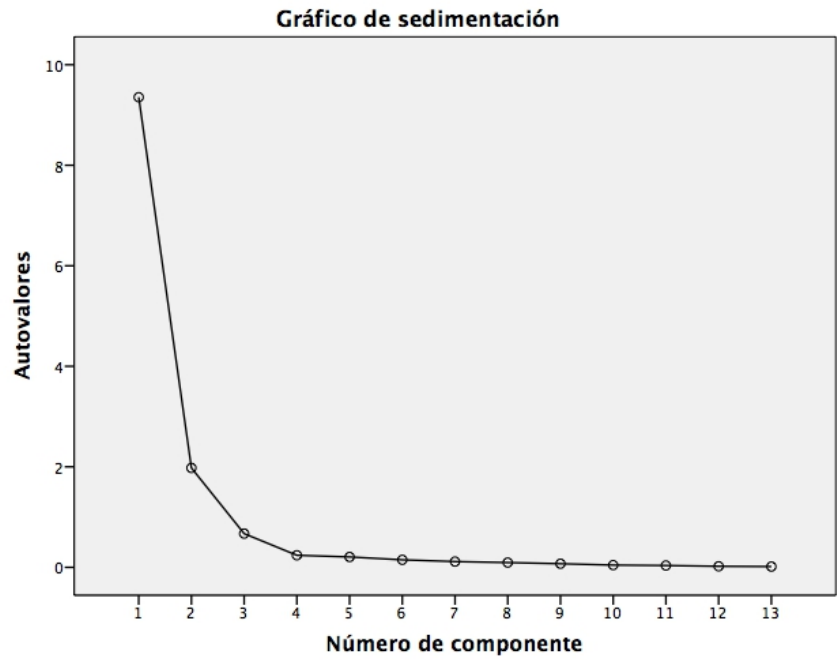

Fuente: elaboración propia. 
Tabla 18. Componentes

Matriz de componentes ${ }^{a}$

\begin{tabular}{|c|c|c|}
\hline & \multicolumn{2}{|c|}{ Componente } \\
\hline & 1 & 2 \\
\hline do processo de ens & ,945 &,- 143 \\
\hline A superv & 932 & -232 \\
\hline Investigação e de coordenação dos cursos; & & \\
\hline A supervisão pedagógica é indispensável ao processo de ensino- & ,641 & ,681 \\
\hline ónon ondómico do Doitorin dl & & \\
\hline $\begin{array}{l}\text { A supervisão pedagógica também é feita pela área académica da Reitoria da } \\
\qquad \text { UKB; }\end{array}$ & 912 & 222 \\
\hline As visitas de supervisão as aulas & 906 &,- 242 \\
\hline A super & ,862 &,- 377 \\
\hline O ISCEI & ,854 &,- 412 \\
\hline $\begin{array}{l}\text { Os chefes de departamentos de ensino realizam visitas de supervisão às } \\
\text { aulas com regularidade; }\end{array}$ & 829 &,- 434 \\
\hline $\begin{array}{c}\text { Há necessidade de realização de sessões de formação em supervisão } \\
\text { pedagógica; }\end{array}$ & ,847 & ,448 \\
\hline $\begin{array}{l}\text { As visitas de supervisão pedagógicas acontecem poucas vezes devido ao } \\
\text { elevado volume de tarefas do pessoal de direito; }\end{array}$ & 949 &,- 194 \\
\hline $\begin{array}{l}\text { Os professores trabalham de forma isolada devido a falta de acções de } \\
\text { supervisão pedagógica; }\end{array}$ & ,922 & ,226 \\
\hline $\begin{array}{l}\text { A supervisão pedagógica no ISCED de Benguela deve ser levada a cabo } \\
\text { por pessoas mais experientes na profissão docente e com conhecimento da } \\
\text { matéria; }\end{array}$ & ,363 & ,630 \\
\hline $\begin{array}{c}\text { A supervisão pedagógica levada a cabo no ISCED de Benguela pouco } \\
\text { satisfaz o desenvolvimento de competências pedagógica dos estudantes em } \\
\text { formação de professores. }\end{array}$ & ,878 & ,382 \\
\hline
\end{tabular}

Método de extracción: Análisis de componentes principales.

a. 2 componentes extraídos

Fuente: elaboración propia.

Tabla 19. Componentes rotados

Matriz de componentes rotados ${ }^{\mathrm{a}}$

\begin{tabular}{|c|c|c|}
\hline & \multicolumn{2}{|c|}{ Componente } \\
\hline & 1 & 2 \\
\hline A supervisão do processo de ensino/aprendizagem sati & ,865 & ,405 \\
\hline A supervisão pedagógica é feita pelos chefes de Departamento de Ensino e & ,904 & ,324 \\
\hline Investigação e de coordenação dos cursos; & & \\
\hline $\begin{array}{l}\text { A supervisão pedagógica é indispensável ao processo de ensino- } \\
\text { aprendizagem; }\end{array}$ & 155 & ,923 \\
\hline $\begin{array}{l}\text { A supervisão pedagógica também é feita pela área académica da Reitoria da } \\
\qquad U K B ;\end{array}$ & ,636 & ,690 \\
\hline As visitas de supervisão as aulas são sistemáticas e planificadas; & ,888 & ,302 \\
\hline A supervisão pedagógica é feita mediante o aviso prévio a & ,926 & ,164 \\
\hline O ISCED possui uma equipa específica para a supervisão & 940 & 131 \\
\hline
\end{tabular}


Os chefes de departamentos de ensino realizam visitas de supervisão às aulas com regularidade;

Há necessidade de realização de sessões de formação em supervisão pedagógica;

As visitas de supervisão pedagógicas acontecem poucas vezes devido ao elevado volume de tarefas do pessoal de direito;

Os professores trabalham de forma isolada devido a falta de acções de supervisão pedagógica;

A supervisão pedagógica no ISCED de Benguela deve ser levada a cabo por pessoas mais experientes na profissão docente e com conhecimento da matéria;

A supervisão pedagógica levada a cabo no ISCED de Benguela pouco satisfaz o desenvolvimento de competências pedagógica dos estudantes em formação de professores.

Método de extracción: Análisis de componentes principales. Método de rotación: Normalización Varimax con Kaiser. a. La rotación ha convergido en 3 iteraciones.

Fuente: elaboración propia.

\section{Análisis Factorial V: Dimensión 4. Resultado de los estudiantes en la CINE Benguela}

Finalizamos el análisis factorial con los resultados obtenidos de la cuarta dimensión del cuestionario. Se presentan los resultados obtenidos una vez realizado el test de esfericidad de Barlett, revelando un chi-cuadrado aproximado a 1002,262, con gl 78 significativo al 0,000; el índice de KMO de Káiser- Mayer- Olkin es de ,927. Estos resultados nos han llevado a ejecutar el análisis factorial, eligiendo el método de Análisis de Componentes Principales (PCA), con rotación de variables, procedimiento Varimax con Kaiser, se ha eliminado el ítem referido a Os professores de Prática Docente I e II devem ser mais exigentes e conhecedores da pedagogia e das Didácticas específicas, ya que la varianza total es igual a 0 , debido al 100\% de respuestas iguales. Los resultados obtenidos se muestran a continuación:

Tabla 20. KMO y prueba de Bartlett

KMO y prueba de Bartlett

\begin{tabular}{|c|c|c|}
\hline Medida de adecuación mu & $\begin{array}{l}\text { le Kaiser-Meyer-Olkin. } \\
\text { Chi-cuadrado aproximado }\end{array}$ & $\begin{array}{r}\text {,927 } \\
1002,262\end{array}$ \\
\hline Prueba de esfericidad de Bartlett & gl & 78 \\
\hline & Sig. & 000 \\
\hline
\end{tabular}


Matriz de correlaciones

\begin{tabular}{|c|c|c|c|c|c|c|c|c|c|c|c|c|c|}
\hline & 4.1 & 4.2 & 4.3 & 4.4 & 4.5 & 4.6 & 4.7 & 4.8 & 4.9 & 4.10 & 4.12 & 4.13 & 4.14 \\
\hline $\begin{array}{l}\text { Os estudantes que terminam a formação de professores são colocados nas } \\
\text { Escolas de Formação de Professores e Magistério Primário; }\end{array}$ & 1,000 & ,896 & ,832 & ,847 & ,854 & 915 & ,873 & ,722 & 820 & ,686 & ,884 & ,561 & ,575 \\
\hline $\begin{array}{l}\text { No final da formação os estudantes mostram-se motivados para exercerem } \\
\text { com competência a profissão; }\end{array}$ & 896 & 1,000 & 838 & 926 & 852 & 848 & 856 & ,788 & 863, & ,793 & 901 & ,750 & 655 \\
\hline $\begin{array}{l}\text { Os estudantes formados dominam as disciplinas pedagógicas e das áreas } \\
\text { específicas de formações; }\end{array}$ & 832 & 838, & 1,000 & ,858 & 906 & ,761 & 844 & 838, & 901 & ,868 & 812 & 691 & ,708 \\
\hline $\begin{array}{l}\text { As competências dos estudantes já formados no ISCED, satisfazem } \\
\text { positivamente as exigências do mercado de trabalho; }\end{array}$ & ,847 & 926 & 858 & 1,000 & 855 & 852 & ,861 & 815 & ,912 & ,840 & ,852 & ,794 & ,723 \\
\hline $\begin{array}{l}\text { A fraca qualidade de muitos estudantes em formação de professores, deve- } \\
\text { se a sua débil aplicação; }\end{array}$ & ,854 & 852 & 906 & 855 & 1,000 & 848 & 920 & ,773 & 894 & ,871 & ,870 & ,717 & 679 \\
\hline $\begin{array}{c}\text { O treinamento da prática pedagógica que se realiza no ISCED, satisfaz o } \\
\text { desenvolvimento das competências pedagógicas dos estudantes em } \\
\text { formação de professor; }\end{array}$ & 915, & 848, & ,761 & ,852 & 848, & 1,000 & 893, & ,591 & ,789 & 699 & ,851 & ,586 & ,548 \\
\hline $\begin{array}{l}\text { Os planos curriculares dos cursos do ISCED pouco satisfazem as } \\
\text { necessidades do subsistema do ensino geral; }\end{array}$ & 873 & 856 & 844 & ,861 & 920 & 893 & 1,000 & 680 & 879 & ,784 & ,880 & 641 & 603 \\
\hline $\begin{array}{l}\text { Necessidade de se rever o programa da disciplina de Prática pedagógica I e } \\
\text { II; }\end{array}$ & ,722 & ,788 & 838 & 815, & ,773 & ,591 & 680 & 1,000 & 847, & ,778 & ,740 & 777 & ,796 \\
\hline $\begin{array}{c}\text { O plano de aula utilizado na disciplina de Prática Pedagógica pouco se } \\
\text { ajusta as exigências do ensino geral; }\end{array}$ & ,820 & ,863 & 901 & 912 & 894 & ,789 & 879, & ,847 & 1,000 & ,861 & 828, & ,755 & ,721 \\
\hline $\begin{array}{l}\text { Os critérios de selecção de professores para a disciplina de Prática } \\
\text { Pedagógica I e II pouco satisfazem; }\end{array}$ & 686 & ,793 & ,868 & ,840 & ,871 & 699 & ,784 & ,778 & ,861 & 1,000 & ,718 & ,797 & ,708 \\
\hline $\begin{array}{l}\text { Os professores de Prática Docente I e II devem ser mais exigentes e } \\
\text { conhecedores da pedagogia e das Didácticas específicas; }\end{array}$ & 884 & 901 & 812 & ,852 & 870 & ,851 & 880 & ,740 & 828, & ,718 & 1,000 & 687 & 658 \\
\hline $\begin{array}{l}\text { Os trabalhos de fim de curso reflectem apenas o fim de um percurso } \\
\text { formativo, não tendo grande incidência na resolução dos problemas que se } \\
\text { investigam; }\end{array}$ & ,561 & ,750 & 691 & ,794 & ,717 & ,586 & 641 & ,777 & 755 & 797 & 687 & 1,000 & ,781 \\
\hline $\begin{array}{l}\text { Os orientadores do trabalho de fim de curso carecem de sessões periódicas } \\
\text { de refrescamento sobre a Metodologia de Investigação Científica. }\end{array}$ & ,575 & 655 & ,708 & ,723 & 679 & ,548 & 603 & ,796 & ,721 & ,708 & 658 & ,781 & 1,000 \\
\hline
\end{tabular}

Fuente: elaboración propia. 
La matriz de correlaciones queda expuesta en la parte superior. En la tabla de matriz de correlaciones se exponen los resultados, se puede observar como los ítems 4.11 no obtiene datos excepto el valor 1 , esto ocurre porque los participantes de la investigación han puntuado la pregunta con el mismo valor en su totalidad, por lo que es constante y no sufre cambios en la tendencia, son dos variables que al eliminarlos por ser imposible su análisis, no formarán parte de los factores/componentes que aparezcan una vez hecha la varianza total.

Vemos en las comunalidades recogidas en la tabla siguiente las variables que más porcentaje consiguen, se marcan en negrita las que obtienen más representación:

Tabla 21. Comunes

\section{Comunalidades}

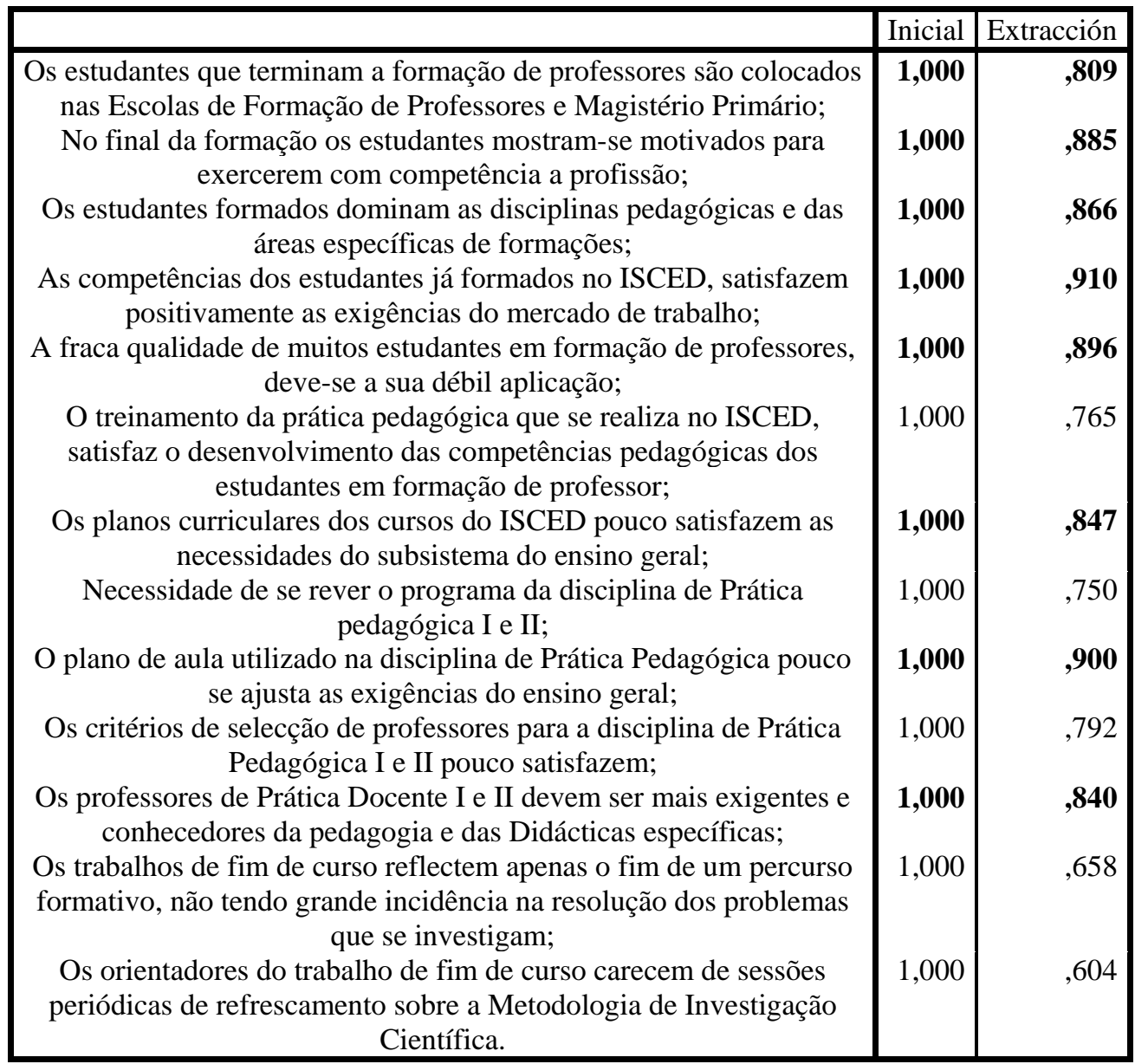

Método de extracción: Análisis de Componentes principales.

Fuente: elaboración propia. 
Seguidamente se muestra la tabla de la varianza total explicada, en la que siguiendo el método de extracción de componentes principales, se explica la variabilidad total por cada componente y la que explica cada uno de ellos. Es un factor el que explica la cuarta dimensión del cuestionario, de las 14 variables existentes, con un 80,942\% total de la varianza, porcentaje que podemos considerar como bueno.

Table 22. Varianza total explicada

Varianza total explicada

\begin{tabular}{|c|c|c|c|c|c|c|}
\hline \multirow[t]{2}{*}{ Componente } & \multicolumn{3}{|c|}{ Autovalores iniciales } & \multicolumn{3}{|c|}{$\begin{array}{l}\text { Sumas de las saturaciones al cuadrado de } \\
\text { la extracción }\end{array}$} \\
\hline & Total & $\begin{array}{c}\text { \% de la } \\
\text { varianza }\end{array}$ & $\begin{array}{c}\% \\
\text { acumulado }\end{array}$ & Total & $\begin{array}{c}\text { \% de la } \\
\text { varianza }\end{array}$ & $\%$ acumulado \\
\hline 1 & 10,522 & 80,942 & 80,942 & 10,522 & 80,942 & 80,942 \\
\hline 2 & 933 & 7,180 & 88,122 & & & \\
\hline 3 & ,356 & 2,735 & 90,857 & & & \\
\hline 4 & ,314 & 2,416 & 93,274 & & & \\
\hline 5 & 244 & 1,879 & 95,153 & & & \\
\hline 6 & 161 & 1,235 & 96,388 & & & \\
\hline 7 & 127, & 975, & 97,363 & & & \\
\hline 8 & ,097 & ,744 & 98,106 & & & \\
\hline 9 & ,070 & ,542 & 98,648 & & & \\
\hline 10 & 058 & 444 & 99,093 & & & \\
\hline 11 & 051, & 389, & 99,481 & & & \\
\hline 12 & 041 & 316 & 99,797 & & & \\
\hline 13 & ,026 & 203 & 100,000 & & & \\
\hline
\end{tabular}

Método de extracción: Análisis de Componentes principales.

Fuente: elaboración propia.

Grafico 4. Sedimentación

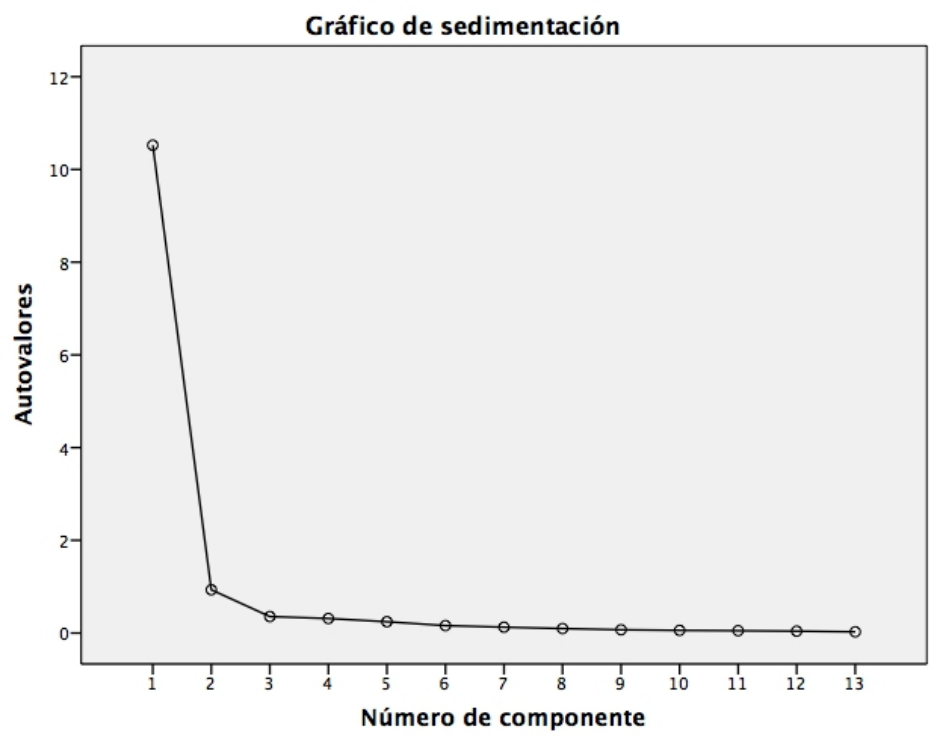

Fuente: elaboración propia. 
En el gráfico de sedimentación de Cattel se ve claramento los resultados expuestos. Al igual que en dimensiones anteriores sólo se extrae un factor.

Tabla 23. Componentes

Matriz de componentes ${ }^{\mathrm{a}}$

\begin{tabular}{|c|c|}
\hline & $\begin{array}{c}\text { Componente } \\
1\end{array}$ \\
\hline $\begin{array}{c}\text { Os estudantes que terminam a formação de professores são colocados nas } \\
\text { Escolas de Formação de Professores e Magistério Primário; } \\
\text { No final da formação os estudantes mostram-se motivados para exercerem } \\
\text { com competência a profissão; } \\
\text { Os estudantes formados dominam as disciplinas pedagógicas e das áreas } \\
\text { específicas de formações; } \\
\text { As competências dos estudantes já formados no ISCED, satisfazem } \\
\text { positivamente as exigências do mercado de trabalho; } \\
\text { A fraca qualidade de muitos estudantes em formação de professores, deve- } \\
\text { se a sua débil aplicação; } \\
\text { O treinamento da prática pedagógica que se realiza no ISCED, satisfaz o } \\
\text { desenvolvimento das competências pedagógicas dos estudantes em } \\
\text { formação de professor; } \\
\text { Os planos curriculares dos cursos do ISCED pouco satisfazem as } \\
\text { necessidades do subsistema do ensino geral; } \\
\text { II; } \\
\text { Necessidade de se rever o programa da disciplina de Prática pedagógica I e } \\
\text { } \\
\text { O plano de aula utilizado na disciplina de Prática Pedagógica pouco se } \\
\text { ajusta as exigências do ensino geral; } \\
\text { Os critérios de seleçãa de professores para a disciplina de Prática } \\
\text { Pedagógica I e II pouco satisfazem; } \\
\text { Os professores de Prática Docente I e II devem ser mais exigentes e } \\
\text { conhecedores da pedagogia e das Didácticas específicas; } \\
\text { Os trabalhos de fim de curso reflectem apenas o fim de um percurso } \\
\text { formativo, não tendo grande incidência na resolução dos problemas que se } \\
\text { investigam; } \\
\text { Os orientadores do trabalho de fim de curso carecem de sessões periódicas } \\
\text { de refrescamento sobre a Metodologia de Investigação Científica. }\end{array}$ & 954, \\
\hline
\end{tabular}

Método de extracción: Análisis de componentes principales.

a. 1 componentes extraído

Fuente: elaboración propia.

\section{Conclusion}

Presentamos los resultados en base a los objetivos propuestos, los cuales se operativizaron a través de los instrumentos aplicados a los docentes, estudiantes y miembros de la dirección de la institución.

Parte de los resultados ponen de relieve la necesidad de mejorar el trabajo docente que se lleva a cabo en la CINE, ya que el número de docentes se considera pequeño para satisfacer las demandas académicas y se debe elevar el grado académico aumentando su formación. 
En cuanto a los objetivos propuestos para la investigación, se pueden tener en cuenta los siguientes aspectos:

El CINE tiene pocos profesores y la mayoría con el título de licenciatura. Muchos de ellos realizan funciones de los jefes de departamento, lo que les lleva a menudo a compaginar la gestion con su horario con las clases. Estos se ven a menudo obligados a salir a mitad de clase, ya que tienen que ir a otras reuniónes de gestion o hacer frente a cualquier cuestión relacionada con la función docente. De esta forma, el aumento del número de profesores permitiria que menos se dedicaran a las funciones de dirección o al menos tener un grupo mas profeionalizado.

Los resultados muestran que la mayoría de los docentes que se hayan en el rango de 5 a 10 años de experiencia de trabajo en la educación superior, estan en la situación de trabajar paralelamente y se añade el hecho de que muchos profesores son licenciados, lo que complica aún más la vision de los resultados negativos.

Otra situación que se encuentra a partir de los resultados, es que muchos profesores dan clases en tres materias en turno de mañana, tarde y noche, $\mathrm{y}$ de diferentes cursos, lo que se percibe como bastante agotador, por muy hábil y eficiente que sea el docente.

Las clases se componen en su mayoría de 50 alumnos, lo que hace que la actividad educativa sea compleja, y hace que sea difícil para el docente utilizar en el proceso dodactico métodos activos de enseñanza-aprendizaje y ademas pueda prestar atención a las características individuales de los estudiantes.

La institución no cuenta con un equipo específico encargado de la orientacion del proceso de enseñanza-aprendizaje que se lleva a cabo, asi como el hecho de hacer un seguimiento sistemático y detectar problemas que se producen en el proceso del día a día. También se apoya la idea de dar mayor prioridad a los alumnos que ya han hecho el la mitad de plan de estudios, lo que permitiría obtener mejores resultados, debido a que muchos de estos sabrian tratar los asuntos educativos de manera diferente en comparación con aquellos que aun no han alcanzado dicha meta.

\section{References:}

1. Aikenhead Glen S. (2009). Educação Científica para Todos. Lisboa: Edições Pedago.

2. Alarcão Isabel \& Roldão Maria do Céu (2008). Supervisão: Um contexto de Desenvolvimento Profissional dos Professores. Lisboa:Edições Pedago.

3. Albino Lopes \& Barrosa Luís (2008). A Comunidade Educativa e a Gestão Escolar: Um Contributo da Gestão Estratégica de Recursos Humanos. Lisboa:Edições pedago. 
4. Alonso, S. \& Palomares, A. (2013). Percepciones de la función tutorial en el Espacio Europeo de Educación Superior del alumnado de la Facultad de Educación de Albacete (Universidad de Castilla-La Mancha, España). En Journal for Educators, Teachers and Trainers, 4(2), 160 - 168.

5. Alves Maria Palmira \& Morgado José Carlos (Org). (2012). Avaliação em Educação: Políticas, Processos e Práticas. Lisboa: De Facto Editores

6. Andrade Maria Margarida de (2003). Introdução a Metodologia do Trabalho Científico. São Paulo: Editora Atlas.

7. Cabral, A. \& Felizardo J. (2005). Currículo do Ensino Primário. Luanda: INIDE editora.

8. Cardoso Jorge Rio (2012). Ser Bom Aluno. Lisboa: Clube do Livro.

9. Dasilva Eugénio Alves (2012). Universidade Agostinho Neto: Quo Vadis? Angola: Kilombelombe.

10. Dieterich Heins (1999). “Novo Guia Para a Pesquisa Científica”. Brasil: Editora da FURB.

11. Eco Humberto (2004). "Como se Faz Uma Tese em Ciências Humanas”. Lisboa: Editorial Presença.

12. Ferreira Bruna Milene (2006). Ofício do professor universitário: o ethos do mestre. En Revista Acadêmica UNIFAN, 3(4). 203-217.

13. Freire Paulo (1996). Pedagogia da autonomia: saberes necessários à prática educativa. São Paulo: Paz e Terra.

14. Flores Maria Assunção \& Simão Ana Margarida Veiga. (Org.). (2009). Lisboa. Edições Pedago.

15. (2005). "Metodologia do Ensino Superior”. 3. ed. São Paulo: Atlas.

16. (5 ed.). São Paulo: Atlas

17. . (2009). "Didática do Ensino Superior". São Paulo. Atlas.

18. Gil Antonio Carlos (2005). Metodologia do Ensino Superior. São Paulo: Atlas.

19. Gil Antonio Carlos. (2009). Didática do Ensino Superior. São Paulo: Atlas.

20. Hargreaves Andy (1998). Os professores em tempos de mudança. Lisboa: Mc Graw.

21. Hargreaves Andy (2004). Ser professor na era da insegurança. En ÁUREA, Adão e Édio, Martins (org.). Os professores: Identidades (re)construídas. Lisboa: Edições Universitárias Lusófonas.

22. Le Boterf Guy (2005). Construir as competências individuais e colectivas. Porto: Edições Asa. 
23. Marcelo, C. G. (1994). Formación del Profesorado para el Cambio Educativo. Barcelona: PPU.

24. Marcelo, C. G. (1999). Formação de professores: para uma mudança educativa. Porto: Porto Editora.

25. Masetto Marcos Tarciso (Org.) (2008). Docência na universidade. 9. ed. Campinas: Papirus.

26. Masseto Marcos Tarciso (2003). Competências Pedagógicas do professor Universitário. São Paulo. Summus Editora.

27. Martins José do Prado (1986). Didática Geral. São Paulo. Editora Atlas S.A.

28. Meirieu Philippe (1998). Aprender...sim, mas como? Porto Alegre: Artmed.

29. Meirieu Philippe (2005). O cotidiano da escola e da sala de aula. Porto Alegre: Artmed.

30. Mezquita Júlio Cerebral \& Rodriguez Jorge Fillo (2004). Como Investigar em Pedagogia. Cuba: Editora Pueblo e Educación.

31. Morgado José Carlos (2012). O Estudo de Caso na Investigação em Educação. Portugal. De Facto Editores.

32. Oliveira Barros de (2010). "Psicologia da Educação". 3a ed. Porto. Livpsic.

33. Pacheco, J. A. (Org.) Alves, M. P.; Flores, M. A.; Morgado, J. C.; Paraskeva, J.; Silva, A. M. \& Viana, I. C. (1999). Componentes do processo de desenvolvimento curricular (p.164). Coleção: Minho Universitária. Braga: Livraria Minho.

34. Pacheco, J. A. (Org.) (2008). Organização curricular portuguesa. (p.11). Porto: Porto Editora.

35. Paraskeva João M. (Org.) (2007). Discursos Curriculares Contemporâneos. Portugal. Edições Pedago.

36. Pereira Júlio Emilio Dinis (2006). "Formação de Professores: Pesquisas Representações e Poder”. $2^{\text {a }}$ ed. São Paulo. Editora Autêntica.

37. Perrenoud, Ph. (1994) Práticas pedagógicas, profissão docente e formação: perspectivas sociológicas. Lisboa, D. Quixote.

38. escolar, Porto, Porto Editora.

39. (1999) Avaliação. Da Excelência à Regulação das Aprendizagens, Porto Alegre, Artmed Editora. 40. - (1999) Construir as Competências desde a Escola, Porto Alegre, Artmed Editora. 41. (1999) Pedagogia Diferenciada, Porto Alegre, Artmed Editora. 
42. (2000) Dez Novas Competências para Ensinar, Porto Alegre, Artmed Editora.

43. Picado Luís (2006). “Ansiedade na Profissão Docente”. $2^{\mathrm{a}}$ ed. Portugal. Edições Pedago.

44. Pinto Jorge et al. (1999). “Dimensões de Formação na Educação: Contributos para um Manual de Metodologia Geral”. Portugal.

45. Pocinho Margarida Dias \& Canavarro José Manuel (2009). “Sucesso Escolar e Estratégias de Compreensão Verbal: Como Compreender Melhor as Matérias e as Aulas”? Portugal. Edições Pedago.

46. Quitembo, A. D. J. (2010). A formação de professores de Matemática no Instituto Superior de Ciências de Educação em Benguela - Angola. Um estudo sobre o seu desenvolvimento. Dissertação apresentada para a obtenção do grau de Doutor em Educação na especialidade de Didáctica da Matemática. Universidade de Lisboa: Instituto de Educação.

47. Queiroz Tânia Dias (2003). Dicionário Prático de Pedagogia. São Paulo. Editora Ridel.

48. Sutta Freddy E. Tanca \& Quispe Gabriel Huaracha (2002). Capacitador Pedagógico. Edições Magister EDIMAG.

49. Tardif Maurice \& LESSARD Claude (2005). O trabalho docente: elementos para uma teoria da docência como profissão de interações humanas. 2. ed. Petrópolis: Vozes.

50. Viana Ilca Oliveira de Almeida (2001). "Metodologia do Trabalho Científico: Um Enfoque Didático da Produção Científica”. São Paulo. Editora Pedagógica e Universitária.

51. Vieira Laurindo (2007). Angola Dimensões Ideológicas da Educação 1975-1992. Luanda: Editorial Nzila.

52. Zayas, C. M. A. (1999). Didáctica. La escola en la vida. Cuba: Editorial Pueblo y Educación. 